\section{A Clean SEM System - Why and How}

Charles E. Bryson III, Surface/Interface, Inc

If you were to examine surfaces in a typical SEM system using any number of surface analysis techniques, I think you'd be surprised at the results. You might expect to see all materials used to construct the vacuum chamber (e.g., plastic or stainless steel), but frequently the spectra will show mostly carbon, the most frequent culprit of SEM contamination. Carbon is adsorbed onto the walls of the vacuum chamber and builds up on the sample, thereby contaminating the SEM system and compromising image quality. By manufacturing and maintaining a clean SEM environment, this problem can be avoided, and you will increase the overall performance of your SEM system

Cleanliness of the SEM environment is important because it can increase the resolution and accuracy of your SEM system while, at the same time, decreasing required maintenance. For example:

1) When taking spatial measurements, carbon contamination changes the dimensions of features on the sample and inhibits accuracy. SEM techniques are now being used more frequently for critical measurements. For example, as line widths in semiconductor designs shrink below $0.8 \mu \mathrm{m}$, more people will be turning from optical inspection techniques to SEM for critical dimension measurement. To ensure a high level of accuracy, the SEM environment must be kept clean.

2) The build-up of carbon and other contaminants on the sample puts a layer of material with a lower atomic number (i.e. carbon) on the surface of a sample that typically has a higher atomic number. Resolution, however, is dependent on the sample - the higher the sample's atomic number, the better the resolution. Therefore, when the sample is coated with a contaminant such as carbon. .. resolution is adversely affected.

3) A clean SEM environment makes the system easier to focus because carbon doesn't build up on the sample, and users don't have to keep moving the beam to new positions to get a clear resolution.

4) A clean SEM environment means less SEM maintenance. Without contaminants in the environment, there is a longer time between liner cleanings. Filament life is also extended because there is a reduced amount of materials present which could either bombard the filament or oxidize on its surface.

Sources of contamination of the SEM system result primarily from excess gases in the vacuum chamber. The sources of these gases include outgassing from materials in the chamber, leaks, and backstreaming. Eliminating these gases is vital to a clean SEM environment.

\section{Design Issues}

The materials used to manufacture the SEM system are often the biggest culprits of outgassing and its corresponding contamination. O-rings should be avoided whenever possible because they are $3 \%$ water by weight and can introduce a significant amount of carbon into the system, usually through lubricants. All-metal gaskets should be used instead. When insulat- ing wires and light pipes, plastic should either be Teflon or polyimide, or replaced with ceramic. These materials, while they may be initially more expensive, have a lower cost of ownership because they significantly lower contamination, thereby reducing maintenance and resulting in better SEM performance.

Whenever practical, the SEM system should be designed without complicated shapes and pumping pathways. This will eliminate trapped volumes that cause contamination.

\section{Manufacturing Issues}

The manufacturing process should be kept as clean as possible. Any procedure that leaves residues of grease, oil, or glue should be avoided.

The finish of all parts in a SEM system is also an important aspect of cleanliness. The finish keeps materials from absorbing or outgassing hydrocarbons. Electropolishing and air baking are two very effective techniques to improve the finish of materials.

\section{Operational Issues}

It is difficult, but not impossible, to effectively clean a SEM system once it is contaminated, so every effort should be made to keep a system clean. Cleanliness can be maintained by adding and adjusting a few key procedures

1) Many existing SEM systems use buna $\mathrm{N} O$-rings. Where O-rings are still necessary, the buna $\mathrm{N} O$-rings should be replaced with Viton ${ }^{\circ} \mathrm{O}$-rings installed without grease when static and very lightly lubricated if moving. Grease is too often used to fill in gaps, and a switch to dry Viton O-rings may necessitate the correction of rough sealing surfaces and insufficient compression, problems that should be corrected anyway.

2) Replace the mechanical roughing pump with a dry pump or add traps and metal hoses to eliminate rough pump backstreaming. Traps, if used, should be cleaned on a regularly scheduled basis. A loadlock system should be incorporated to avoid opening the chamber and contaminating the environment from repeated venting to air, and the system should be maintained above transition pressure between molecular flow and laminar flow, even when not in use. When using a leak detector, a dry pump is preferable to oil pumps, which can also introduce contamination.

3) If the chamber must be opened, several procedures would be observed. The inside of the chamber should never come in contact with bare hands or arms - clean, properly treated gloves and sleeves should be worn when handling internal components. Any parts or samples that are taken out of the chamber should be wrapped in fresh aluminum foil to keep them clean. After opening the chamber, it should be backfilled with nitrogen or helium to purge as much water as possible from the system before samples are loaded.

\section{The Results}

Careful attention to design and maintenance, as described above, will result in a significant reduction in carbon build-up in your SEM system. The graph below shows the reduction in carbon build-up over time, as measured by our AES system, in a cleaned-up SEM verses the same system prior to clean-up and the results improve with time. In the cleaned-up AES, after a month, less than $5 \%$ build-up was detectable by AES analysis.

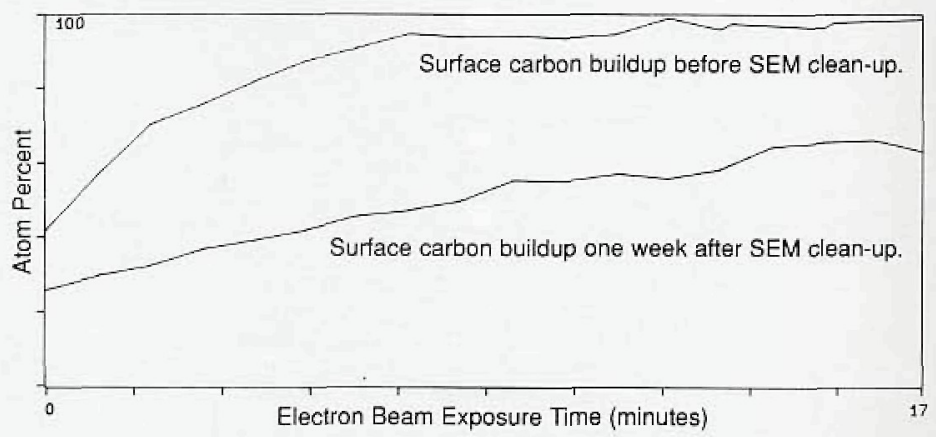

A clean SEM system means that equipment will be easier to focus, maintenance will be cheaper and less frequent, and accuracy and resolution will increase. In short, cleanliness will enable you to get the most from your SEM system. 


\section{ROBINSON DETECTOR}

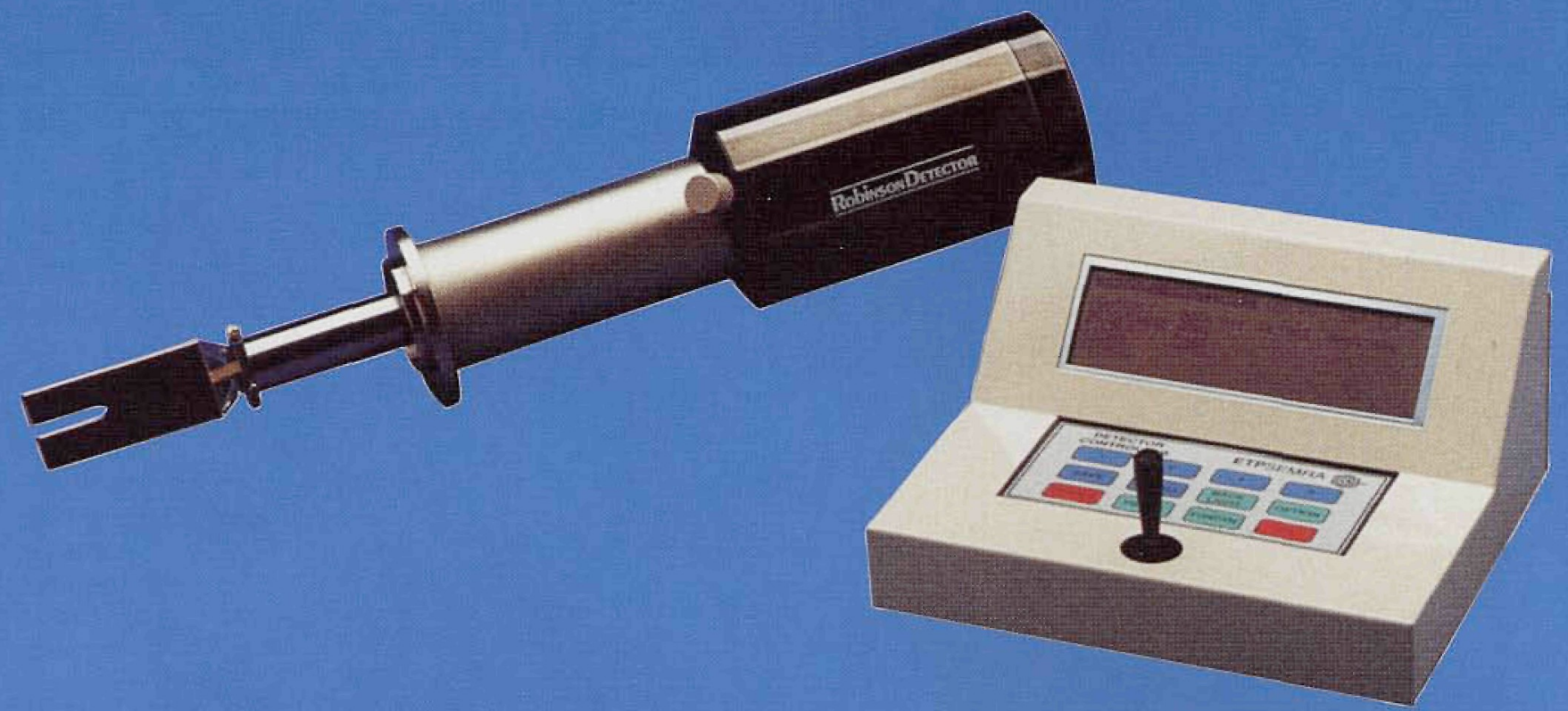

\section{WITH ANOTHER LEAP IN SEM IMAGING TECHNOLOGY

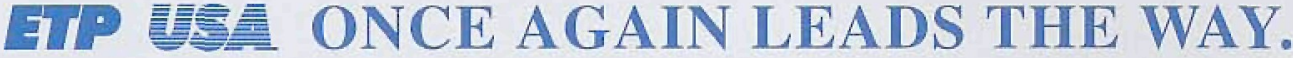

RS-232 Communication.

Intuitive Joystick Operation.

Optimum Bandwidth Selection.

True TV Imaging With Out Edge Smearing.

Retractable Design for Maximum Flexibility.

Computer Interface via Windows Now Available.

8 Line - 40 Character LCD Display of Detector Status.

Instant Save and Recall of Operating Conditions.

Microprocessor Control of the Robinson Detector.

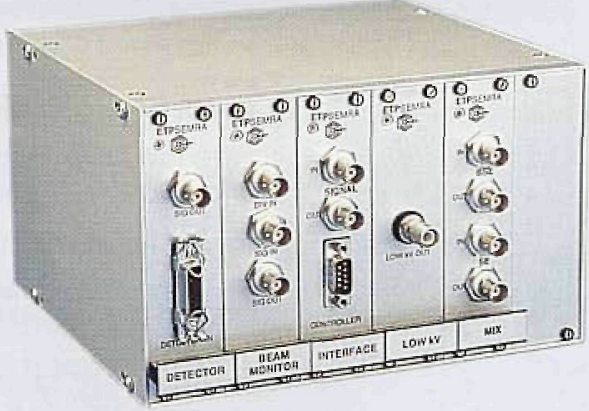

Total Accessory Operation without using Valuable SEM Console Space.

At Atomic Number 30, Discrimination is Better than 0.1 Atomic Numbers.

2000mm Active Surface Area, 5mm Thick at Beam Entry Point, 5:1 S/N at 1 PA, 10KV.

Extensive Accessory List including: Low Accelerating Voltage Operation, SE-BSE Signal Mixing, Selected Phase Imaging, Motorized Retraction, Scanning Transmission, Cathodoluminescence Detection and Much More...

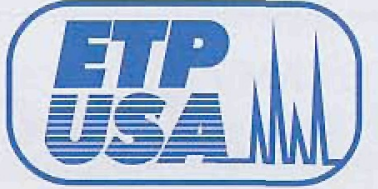

ELECTRON DETECTORS, INC.

1650 HOLMES STREET • LIVERMORE, CA 94550

TEL: (510) 449-8534 1 (800) 8ETP USA FAX: (510) 449-8996 


\section{ETP-USA \\ SEM Chamber View System}

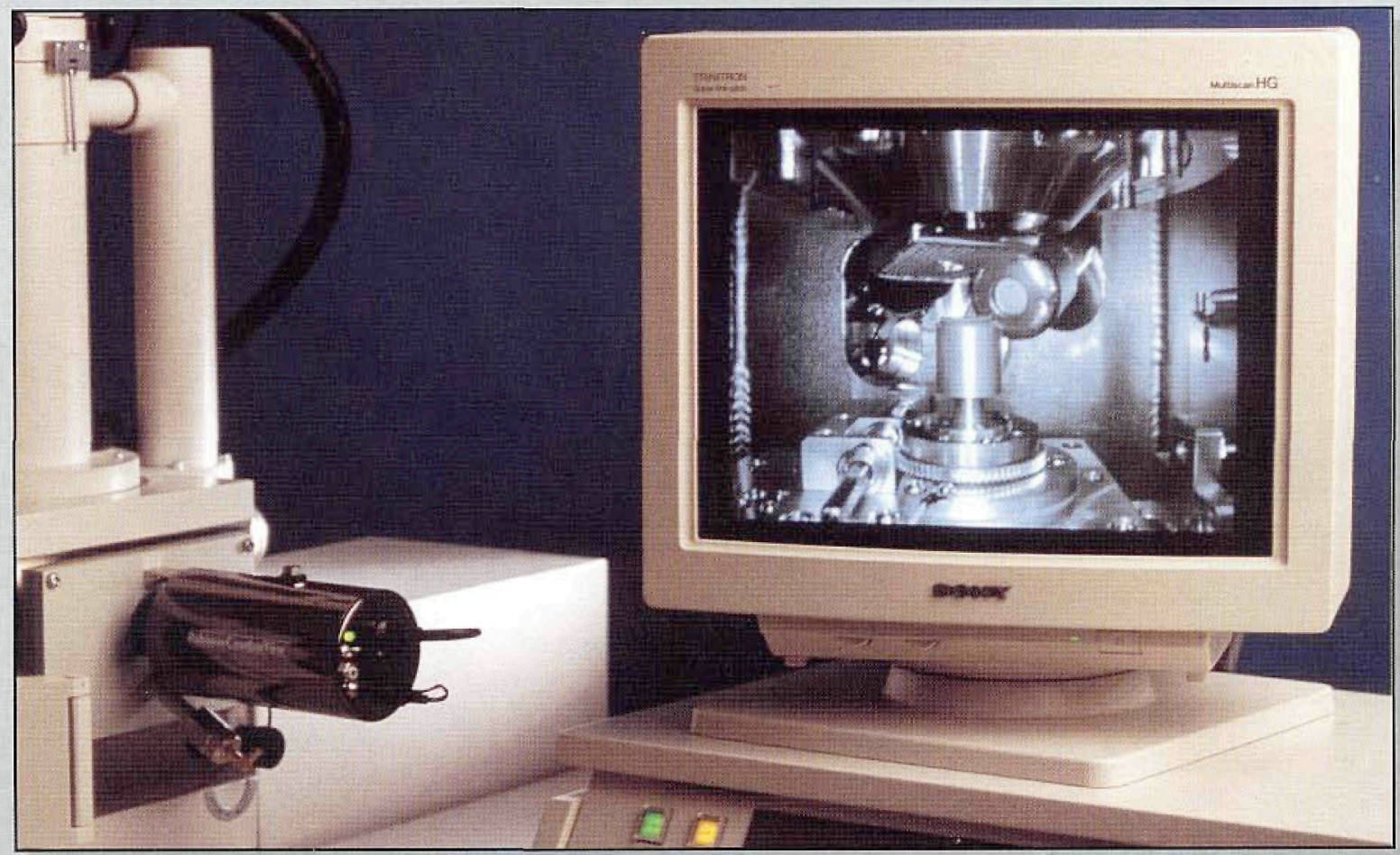

ETP Chamber View mounted on SEM with SEM chamber image

$\downarrow \quad$ ETP infrared SEM Chamber Viewer allows continuous monitoring of SEM chamber interior.

$ـ \quad$ Ideal for viewing specimen orientation or locating a specimen in a multi-specimen group.

- Avoid damage to specimens, final lens, x-ray, SE, BSE detectors, and allow optimum positioning of all.

$\downarrow \quad 2 \times$ zoom lens optionally available.

ـ No electronic rack space or external boxes required.

$\downarrow \quad$ Diffuse illumination avoids excessive brightness with flat specimens such as IC wafers.

$\perp$ Outstanding depth of field.

- Includes monochrome monitor and necessary cables for simple installation.

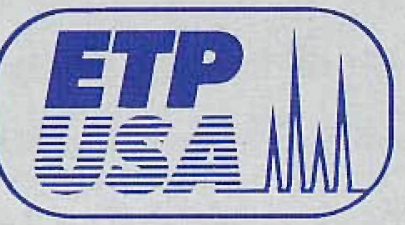

For more information on the ETP Chamber View System or the Robinson Detector call 1-800-8-ETP-USA or write ETP-USA today. 


\section{Leica Redefines SEM ...}
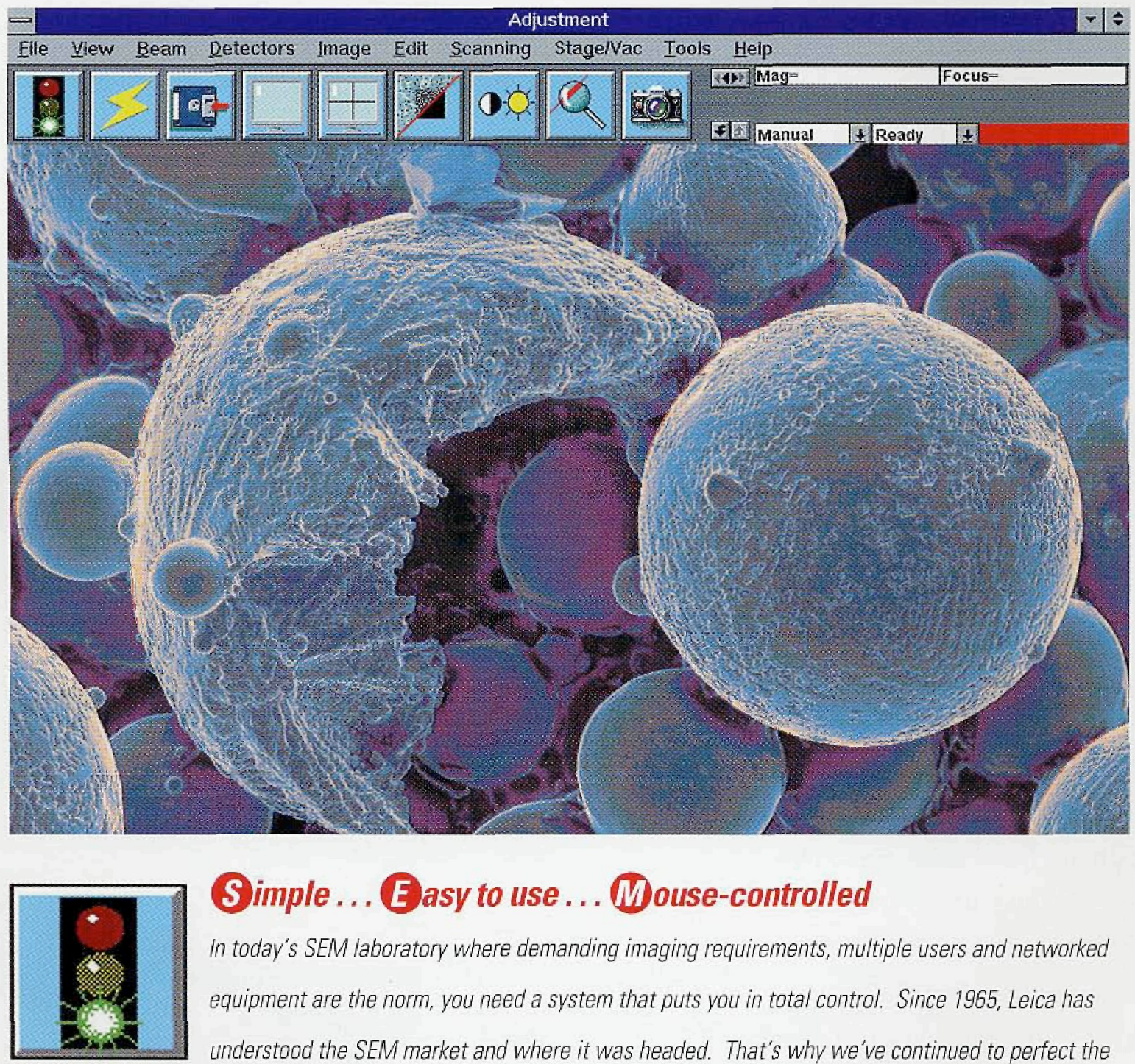

\section{Simple...E Easy to use.... Mouse-controlled}

In today's SEM laboratory where demanding imaging requirements, multiple users and networked equipment are the norm, you need a system that puts you in total control. Since 1965, Leica has understood the SEM market and where it was headed. That's why we've continued to perfect the belief we've had all along — build high resolution optics, offer an array of advanced features, and develop an SEM control system powerful enough for today's needs, yet flexible enough for tomorrow's.

Leica's Stereoscan 400 series provides just that performance you can count on, superb image quality and a common sense approach to system operation.

Ready, set, go... now you're in control! For the name of the Leica representative nearest you, call us at 1-800-248-0123 Ext. 7041 or fax 708/405-0147. Micrograph above of nickel powder used for powder metallugy applications.

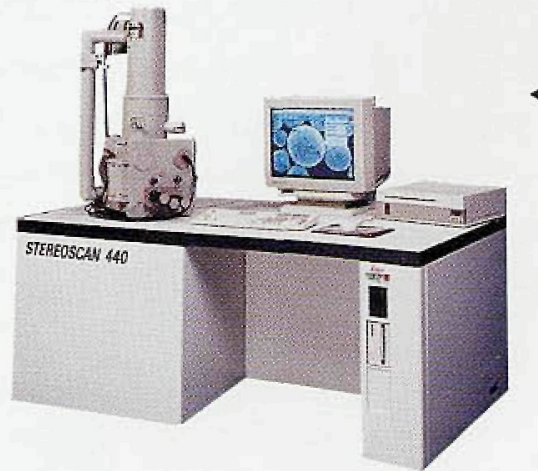

Leica's Stereosean 440 features an MS-Windows ${ }^{T M}$ based interface with extensive automation capabilities, SuperVGA display, large specimen chamber, and optional EDX integration and computer networking. 


\section{If you think WDX microanalysis is not for you}

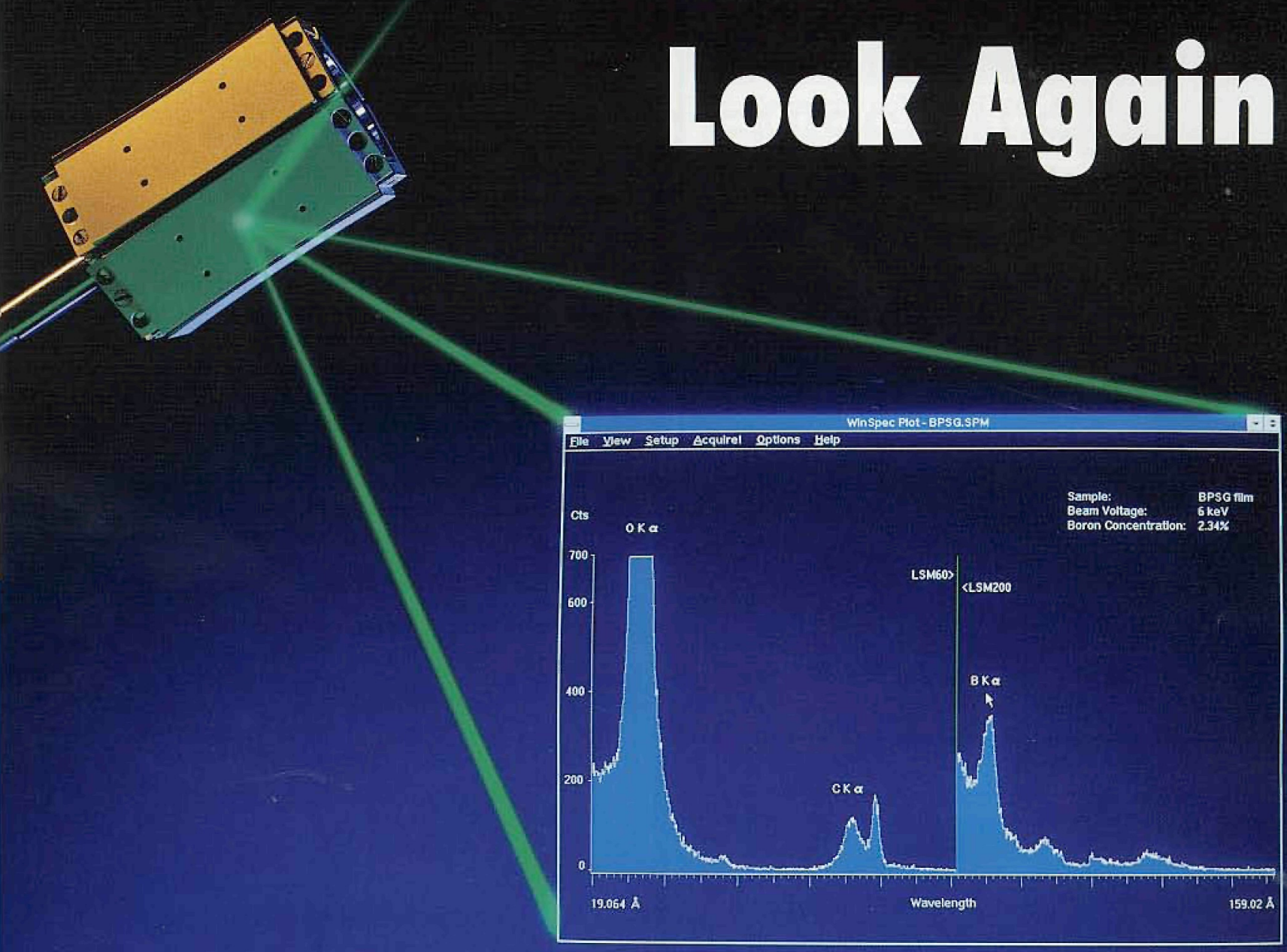

It's eusy to get more precise results using the new WDX spectrometers from Microspec
It is well recognized that WDX delivers outstanding X-ray performance for microanalysis. But you may not know how easy it can be to obtain these superior results in your lab.

With their high elemental sensitivity, accurate quantitative light-element analysis, and superb spectral resolution, the new WDX-400/600 spectrometers from Microspec allow analysis that can't be done with EDX or other analytical techniques. These systems provide the high precision needed to ensure reliable results. At the same time, the Windows ${ }^{\mathrm{TM}}$ environment makes the WDX-400/600 systems easy to use and facilitates integration into your lab. They are compatible with most SEMs and with most SEM and EDX computers. And Microspec provides full support for instrument use, with training courses and a team of service engineers.

Take a closer look at WDX. Call today for a product brochure and application notes that include direct comparisons of WDX and EDX results on samples similar to yours. 


\section{TIMES THE X-RAY COUNT RATE ON YOUR FIELD EMISSION SEM!}
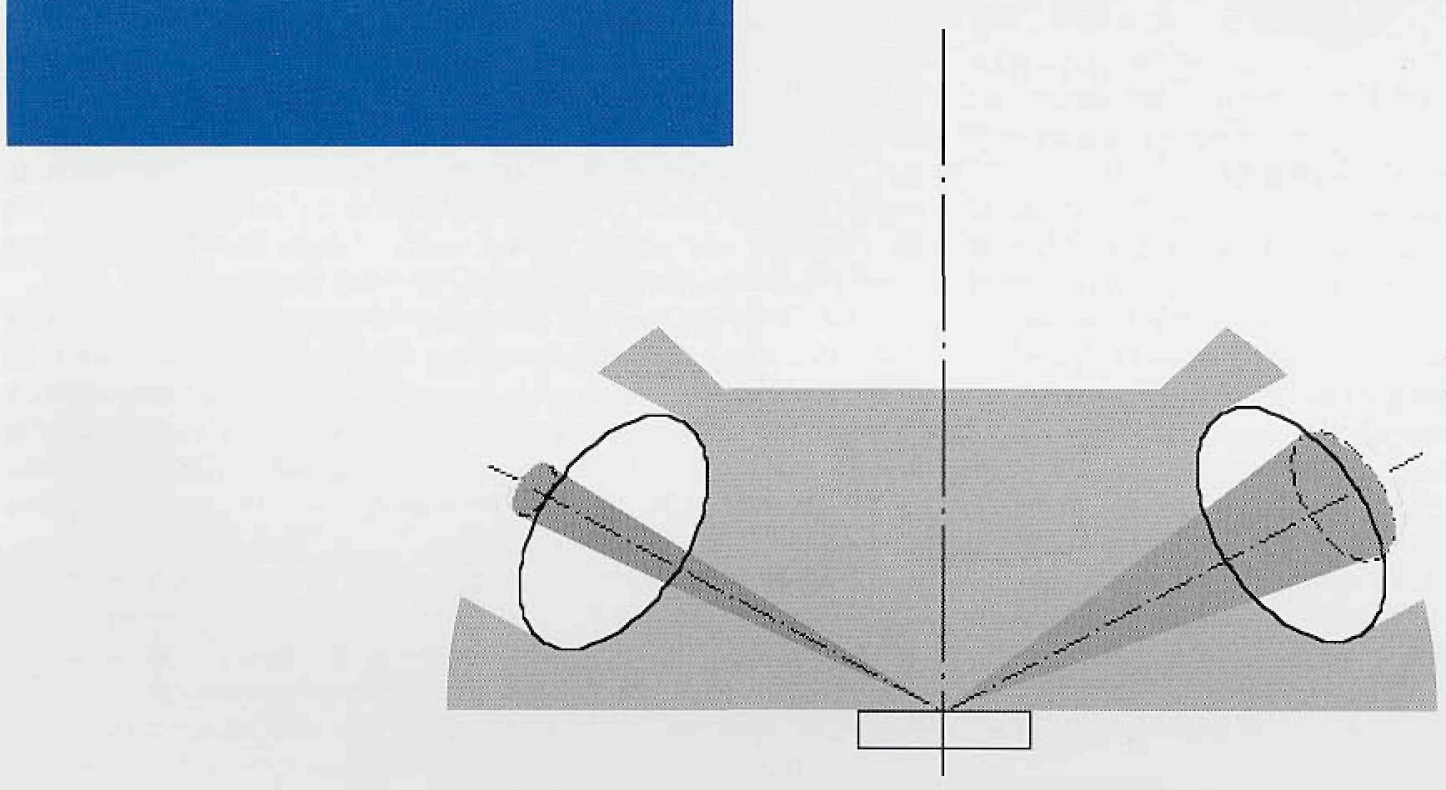

PRISM $^{60}$

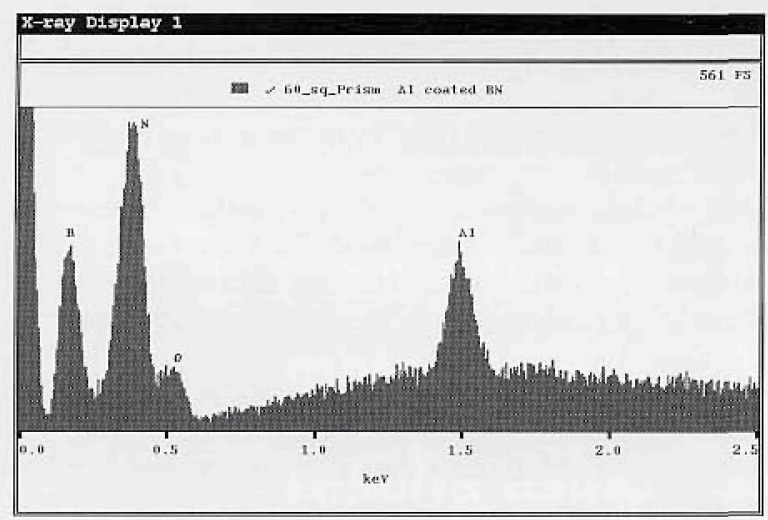

\section{PRISM ${ }^{60}$ EDS Detector}

- $60 \mathrm{~mm}^{2}$ active area $\mathrm{x}$-ray detector

- Standard size detector housing

- Excellent Light element sensitivity

- 25:1 Boron Peak/Valley ratio

- Patented Digital Pulse Processing. . . ... turns dead time into counting time!

With the PRISM ${ }^{60}$ Digital X-ray Detector you no longer have to compromise good imaging conditions to get rapid and precise $\mathrm{x}$-ray data. Six times more detection area means six times more data. .

... without sacrificing high resolution SEM operation.

Improve the speed of $\mathrm{x}$-ray analysis on any SEM. . Call PGT today!

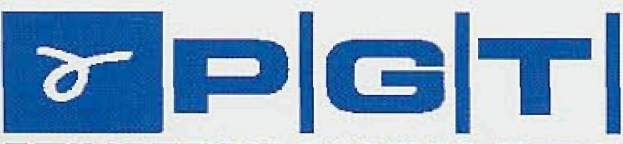




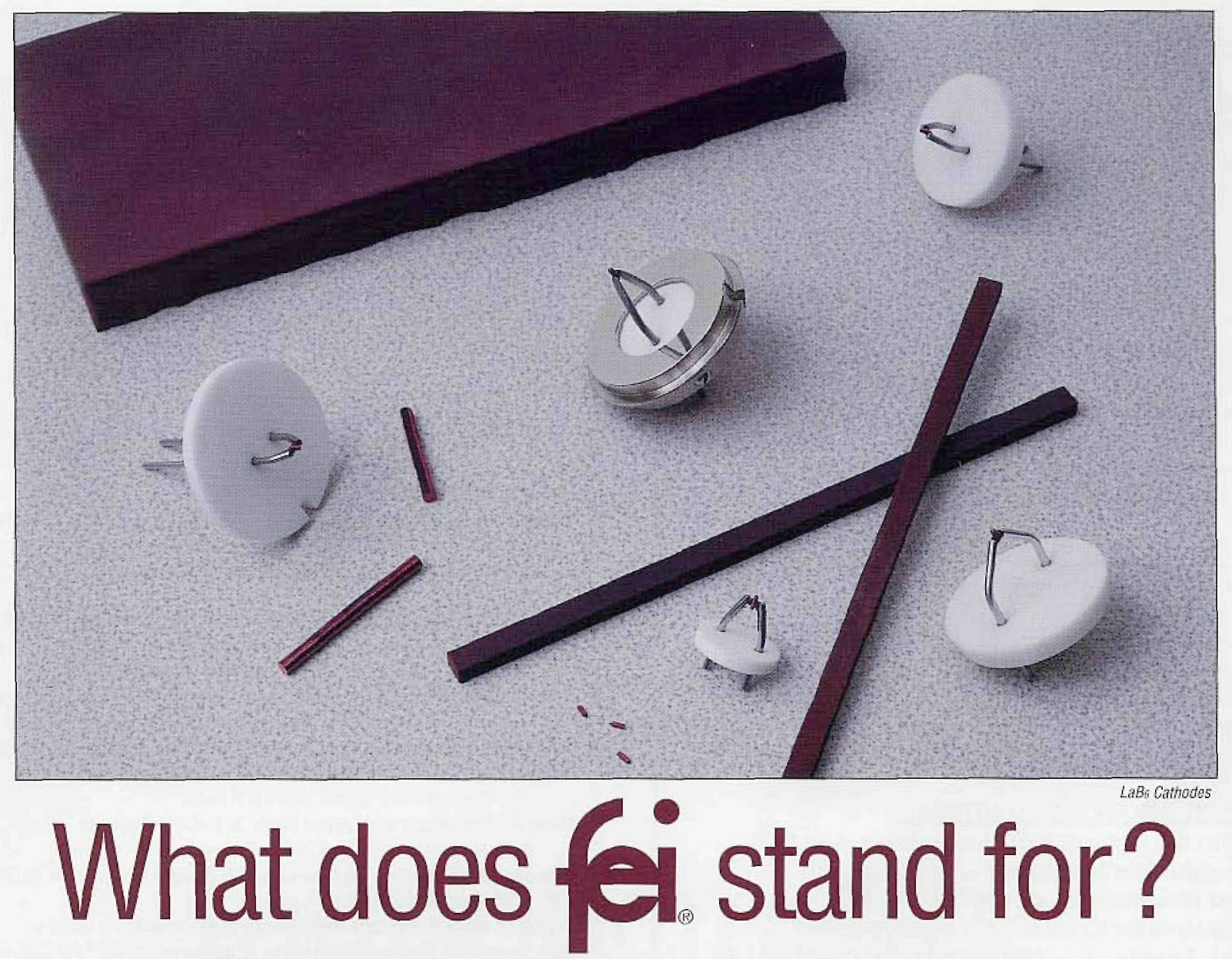

FEl's Mini Vogel Mount was the first true long-life, high stability LaB6 cathode for all electron beam instruments. The MVM is the economical emitter choice, providing consistent high quality performance and the best cost-per-use value. FEl is the innovator in the application of field emission technology...

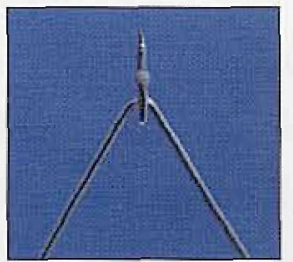

Field Emission Cathodes

FEl supplies Schottky field emitters to EM manufacturers worldwide. Schottky emission's high current intensify has established it as the preferred electron source for high resolution SEM, TEM, Auger, ESCA, EDX, and lithography.

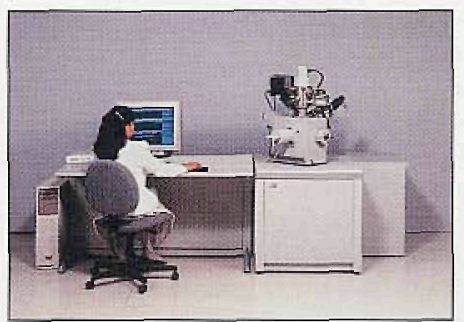

FIB Workstations

Focused ion beam micromilling workstations range from the 8"-wafer compatible model to the economical 2" small sample model ideal for semiconductor, biological, TEM, and MEMS specimens.

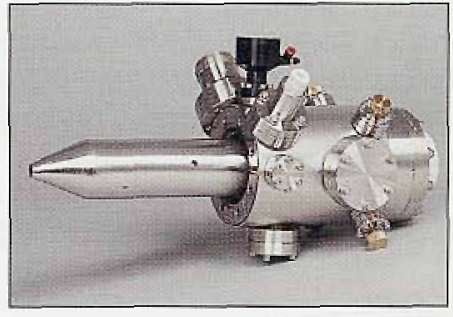

UHV Electron and Ion Columns FEI's high current density, UHV field emission focusing columns easily install on existing SIMS, Auger, and SEM instruments.

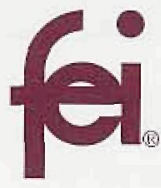

FEI Company

7451 NE Evergreen Parkway

Hillsboro, OR 97124-5830

(503) 640-7500 Fax (503) 640-7509

email:dlh@feico.com

Now, when you think of FEl, you'll know we are the Specialists in Field Electron and Ion Technology. 
McCrone Research Institute CHICAOO

\section{MICROSCOPY COURSES}

\section{Chicago, IL, August 1994 - May 1995}

\section{COURSES WITH GENERAL FOCUS}

Applied Polarized Light Microscopy - Offered Monthly

Forensic Microscopy - August 29-September 3, November 28 -

December 21994 and April 3-7 1995 *

Microscopy for Art Conservators - January 9-13 1995

Pharmaceutical Microscopy - February 13-17 1995*

\section{SPECIALIZED COURSES - METHODOLOGY}

Photomicrography - August 8-12, October 3-7 1994 and March 20-24 1995

Crystal Morphology \& Optics - September 26-30 1994

Fusion Methods - December 5-9 1994

Particle Identification and Manipulation - Nov. 7-11 1994

Special Methods in Light Microscopy-A - October 10-14 1994

Sample Preparation Methods - December 12-16 1994

\section{SPECIALIZED COURSES - MATERIALS}

Identification of Small Particles - February 6-10 1995

Wood and Pollen Microscopy - April 24-28 1995

Mineral Identification - October 24-28 1994

Soils Analysis for Criminalists - August 1-5 1994

Forensic Examination of Building Materials - Mar 13-17, ‘95

Paint Microscopy - September 12-16 1994

Fiber Identification - Hayward, CA - January 23-27 1995

Polymer, Fiber \& Film Microscopy - September 12-16 1994

Microscopy and Microchemistry of Polymers - September 19-231994

\section{ASBESTOS COURSES}

Microscopical Identiflcation of Asbestos - Offered Monthly * Advanced Asbestos Identification - Offered Bi-Monthly * Quantitative Asbestos Analysis - May 2-4, November 14-16, 1994 and April 3-5, 1995 *

Asbestos Fiber Counting (NIOSH 582) - August 15-19, October 3-7, December 12-16 1994 and March 20-24 1995 *

\section{ADVANCED COURSES**}

Computers in Microscopy - Hayward, CA Feb 27-Mar 31995

Microchemical Methods - October 31-November 4 *

Advanced Microchemical Methods - August 22-26 1994

Microscopical Study of Paints and Extenders - Santa Ana,

CA - March 20-24 1995

\section{ELECTRON MICROSCOPY COURSES}

TEM Introduction - September 12-16 1994

TEM Asbestos Analysts - Nov 7-11 1994 and Mar 27-31 1995

\section{For Registration and Additional Information contact}

Nancy Daerr, McRI, 2820 S. Michigan Avenue

Chicago, IL 60616-3292; (312) 842-7100

* Also offered in Hayward,CA; Seattle, WA or Santa Ana, CA.

** Prerequisite required.

\section{Current Research at NCEM}

The National Center for Electron Microscopy is a DOE-designated national user facility and is available at no charge to qualified researchers. Access is controlled by an external steering committee. Interested I researchers may contact Gretchen Hermes at (510)486-5006.

The following papers, available at no cost, reflect current research at NCEM and may be ordered from:

\section{Theda Crawford \\ National Center for Electron Microscopy \\ Lawence Berkeley Laboratory \\ One Cyclotron Road, MS72 \\ Berkeley, CA 94720}

NCEMSS User's Guide - PUB658 / M.A. O'Keefe \& R. Kilaas

Morphology and Crystallography of $\mathrm{Cr}$ Precipitates in a Cu- 0.33 wt.\% CR . \#34063/ C.P. Luo, U. Dahmen \& K.H. Westmacott

Novel Phases in the Oxidation of $\gamma$-Titanium Aluminum - \#34812/RW Beye \& R. Gronsky.

Microstructure and Epitaxy of $c$-axis Oriented Single Crystal Cobalt Films Grown on Rigid Underlayers - Un-numbered I K.M Krishman. Y. Honda, Y. Hirayama \& $M$ Futamoto.

Defect Control During Solid Phase Epitaxial Growth of SiGe Alloy Layers

Ḧ33574/S im, J. Washburn, R. Gronsky. N.W Cheung \& K M. Yu

Giant Magnetoresistance and Microstructural Characteristics of Epitaxial Fe-Ag and Co-Ag Granular Thin Films - \#34587 / N. Thangaraj, C. Echer, KM. Krishman, R.F.C. Farrow, R.F. Marks, and S.S.P Parkin

Magnetic Anisotropy and Lattice Strain in Co/Pt Multilayers - \#32819/B. Zhang K.M. Krishman, C.H. Lee \& R.F.C. Farrow.

ISelected Area Polishing for Precision TEM Sample Preparation - \#33607 / J. B. Liu, B.M. Tracy \& R. Gronsky.

Evolution of Ge Precipitate Morphology in Al - \#35332/ U Dahmen.

1 High Resolution Electron Microscopy of Intefaces - \#34607 / U . Dahmen.

Image Processing to Extract Line Information from Micrographs - \#33829/ J. Turner, M.A. O'Keefe \& S. Paciornik.

A Method for Direct Measuements of Specimen Noise in HREM Images - $\# 33821$ IS. Paciomik, R. Kilaas, U. Dahmen \& M.A. OKeefe

Using Convergence and Spread of Focus Parameters to Model Spatial and

Temporal Coherence in HRTEM Simulations - \#33822/ JO Maim \& M.A. OKeefe.

The Effects of Small Crystal Tilts on Dynamical Scattering: Why Simulated

Images are Thinner Than Experimental Ones - \#33823/M.A. O'Keefe \& V Radmilovic

Amorphization of $\mathrm{Al}{ }_{10}\left(\mathrm{Vx}{ }^{*} \mathrm{C}_{\mathrm{r}}{ }^{*}\right)$ Intermetallic Phase - $\# 35347 / \mathrm{V}$. Radmilovic, $\mathrm{R}$ Kilaas \& $\mathrm{G}$. Thomas

Interpretation of HRTEM Images by Image Simulation: An Introduction to Theory and Practive - \#35348/M.A. OKeefe

Structure and Chemical Composition of Pt-Ru Nanoparticle Supported on Carbon Black - \#35351 IV. Radmilovic, H. Gasteiger \& P. Ross.

$\mathrm{CaF}_{2}$-Si(111) as a Model lonic-Covalent Systems: Transition from Chemilsorption to Epitaxy - \#32855/G.C.L. Wong, D Loretto, E. Rolenberg, M.A Olmstead \& C.A. Lucas

Using Coherent Illumination to Extend HRTEM Resolution: Why we Need a FEG- I

TEM for HREM - \#33157 / M.A. OKeefe.

3-D Imaging of Crystals at Atomic Resolution - \#35156 / M.A. O'Keefe, Kk.H Downing. H.R. Wenk \& H. Meisheng.

Assessment of Specimen Noise in HREM Images of Simple Structures - \#33720/ S. Paciornik, R. Kilaas \& U. Dahmen.

Dynamic Observations of Interface Motion During the Oxidation of Silicon \#34392/F.M. Ross, J.M. Gibson, \& R.D. Twesten

Crystallography of Co-Pt Multilayers and Nanostructures - \#32290/B. Zhang, K.M. Krishman \& R.F C. Farrow

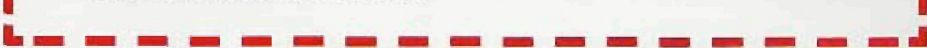




\section{Instruments with the - il advantage}

\section{The SPI-Module \\ Sputter/Carbon Coating Systep}

Vacuum Control Base (SPI \# 11425-AB)

SPI advantage: Continuously moveable sample table in the vertical direction for best results

Sputter Coater Module (SPI \# 11430-AB)

SPI advantages: Faster coating with magnetic design. Unique test mode permits off removal of contaminants before coating actually begins.

Carbon Coater Module (SPI \# 11428-AB)

SPI advantages: Both carbon rod and carbon fiber heads available for optimum coating conditions for different samples. Special unique test mode to make sure all adsorbed moisture in the carbon rod (or fiber) is "burned off" prior to the commencement of coating.

Quartz Crystal Thickness Monitor (SPI \# 12161-AB)

Etch Mode (SPI \# 11449-AB)

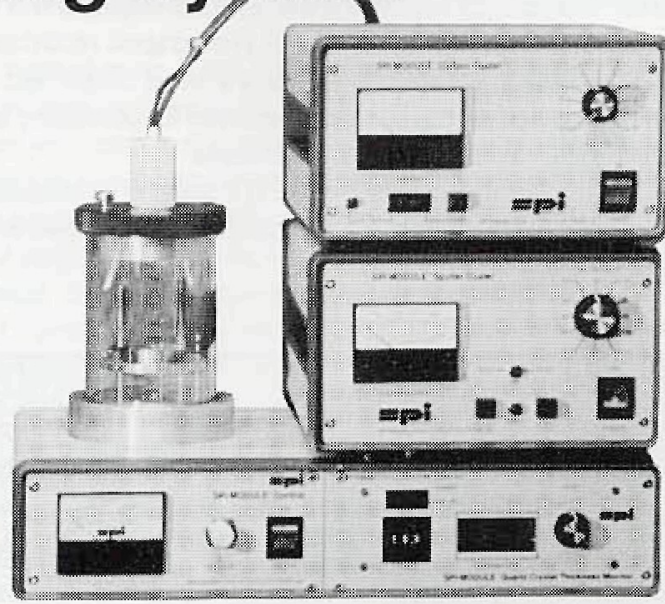

The SPI" Sputter/Carbon Coating System

Modules from top to bottom are- the Carbon Coater Module. the Sputter Coater Module and the Control Module with the optional Quartz Crystal Thickness Monitor.

Air Bleed Control Valve - Room Temperature Operation Rugged Circuitry - Compact, Efficient Design - Safety Protected

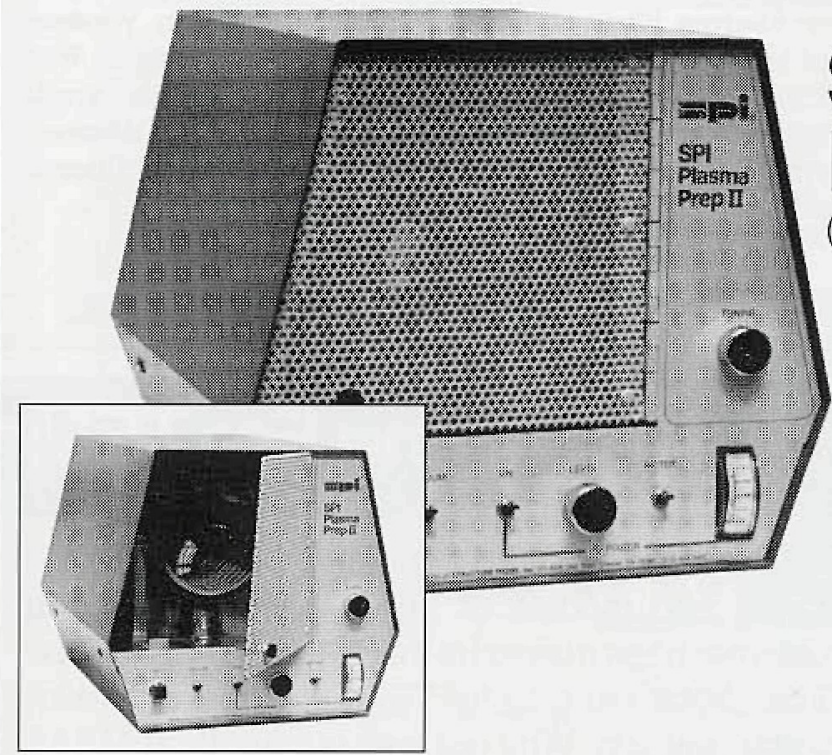

\section{SPI Plasma Prep II ${ }^{\mathrm{m}}$ Bench-Top Plasma Etcher (SPI \# 11005)}

\section{SPI advantages}

- Eliminates the need for high temperatures and wet chemicals.

- Improves surface wettability and "conditions" TEM grids.

- Removes photoresist residues and passivation layers.

- Removes organic residues and "conditions" surfaces.

- Will not contaminate the sample.

- Retains fine structural detail.

- Optional "Fomblin" charged pump for $\mathrm{CF}_{4}$ operation.

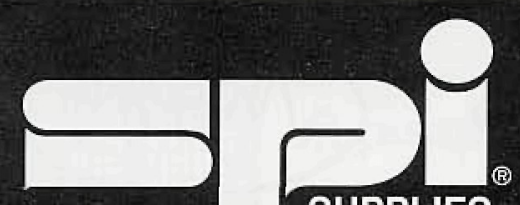

Call us Toll-Free at 1-800-2424-SPI

SPI Supplies Division of Structure Probe, Inc.

SUPPLIES $1-610-436-5400$ - FAX: 1-610-436-5755

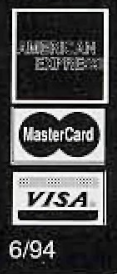

